dr hab. Zofia WYSZKOWSKA, prof. nadzw UTP

Wydział Zarządzania Uniwersytet Technologiczno-Przyrodniczy w Bydgoszczy

zofiawyszkowska@cps.pl

mgr Sylwia SERWATKA-BOBER

Collegium Medicum UMK w Bydgoszczy

sylwia.serwatka@wp.pl

DOI: $10.15290 /$ oes.2018.01.91.14

\title{
REGIONALNE ZRÓŻNICOWANIE ROZWOJU GOSPODARCZEGO A STRUKTURA DEMOGRAFICZNA W WOJEWÓDZTWACH W POLSCE
}

\begin{abstract}
Streszczenie
Praca obejmuje problematykę regionalnego zróżnicowania rozwoju gospodarczego i struktury demograficznej w Polsce w latach 2006 i 2015. Celem pracy jest identyfikacja regionalnego zróżnicowania w zakresie rozwoju gospodarczego i w zakresie struktury demograficznej w Polsce oraz utworzenie rankingu województw pod względem zróżnicowania w zakresie rozwoju gospodarczego i struktury demograficznej.

Źródło danych stanowiły informacje pochodzace z Banku Danych Lokalnych Głównego Urzędu Statystycznego. Okres badania to lata 2006 i 2015. W pracy została zastosowana jedna z metod taksonomicznych tzw. metoda wzorcowa. Zastosowanie metody taksonomicznej pozwoliło na porównywanie i porządkowanie województw z punktu widzenia rozwoju gospodarczego i struktury demograficznej. Województwa zostały uporządkowane według analizowanych zjawisk za pomoca jednej zagregowanej wielkości, czyli tzw. zmiennej syntetycznej. Zmienna syntetyczna pozwala na przejście z opisu wielowymiarowego na jednowymiarowy, co oznacza, że jednostki charakteryzujące się wieloma cechami można opisać za pomoca jednej zagregowanej wielkości.

Badania wykazały, że w analizowanych latach najlepsza sytuacja pod względem rozwoju gospodarczego i w zakresie struktury demograficznej wystapiła w województwie wielkopolskim. Najgorszą sytuację pod względem analizowanych zjawisk odnotowano w województwie świętokrzyskim.
\end{abstract}

Słowa kluczowe: rozwój gospodarczy, struktura demograficzna, sektor publiczny

\section{REGIONAL DIVERSIFICATION OF ECONOMIC DEVELOPMENT AND DEMOGRAPHIC STRUCTURE IN VOIVODSHIPS IN POLAND}

\section{Summary}

The study covers issues of regional diversification of economic development and demographic structure in Poland in 2006 and 2015. The aim of the work is to identify regional differences in economic development and demographic structure in Poland and to establish a ranking of voivodships in terms of differentiation of economic development and demographic structure.

Information originating from the Local Data Bank of the Central Statistical Office [Główny Urząd Statystyczny] was the source of the data. The study period covers 2006 and 2015. One of the taxono- 
mic methods (so-called standard method) was used in the study. Using the taxonomic method allowed us to compare and organize the voivodships from the point of view of economic development and demographic structure. They were organized according to the analyzed phenomena by means of one aggregated size i.e. synthetic variable. The synthetic variable allows moving from a multidimensional description to a one dimensional one, which means that multiple units can be described by one aggregate size.

Research showed that in the analyzed years the best situation in terms of economic development and demographic structure occurred in the Wielkopolskie voivodship, while the worst situation in terms of the analyzed phenomena was recorded in Świętokrzyskie voivodship.

Key words: economic development, demographic structure, public sector

JEL classification: O15, R23, J11

\section{Wstęp}

Do głównych wyzwań, jakie stoją współcześnie przed sektorem publicznym zaliczamy m.in. nierównomierność rozwoju gospodarczego i postępujący proces starzenia się społeczeństwa. Na poziom rozwoju gospodarczego wpływa wiele czynników, a analiza wpływu tych czynników na dynamikę rozwoju gospodarczego pozostaje jednym $\mathrm{z}$ najważniejszych zagadnień $\mathrm{w}$ ekonomii. Postępujący proces starzenia się ludności jest współczesnym zjawiskiem demograficznym. Jego skala i natężenie z roku na rok jest coraz większe. Proces ten oprócz Polski obejmuje także społeczeństwa w pozostałych krajach Europy i innych wysoko rozwiniętych krajach świata [Kurek, 2008, s. 7]. W wyniku tego procesu, w określonej perspektywie czasu prognozuje się, że dojdzie do istotnej zmiany proporcji między ludźmi młodymi i starymi. Liczba osób w wieku przedprodukcyjnym maleje, a liczba osób $\mathrm{w}$ wielu poprodukcyjnym rośnie. Celem pracy jest identyfikacja regionalnego zróżnicowania województw w zakresie rozwoju gospodarczego i struktury demograficznej w Polsce oraz utworzenie rankingu województw pod względem analizowanych zjawisk.

\section{Rozwój gospodarczy a struktura demograficzna}

Rozwój gospodarczy obejmuje zmiany jakościowe i ilościowe podstawowych wielkości makroekonomicznych. Zmiany te często określa się jako postęp cywilizacyjny [Noga, 2008, s. 6]. Rozwój gospodarczy inaczej to zmiany struktury potencjału wytwórczego gospodarki, struktury produkcji i konsumpcji, stosunków społecznoekonomicznych oraz systemu funkcjonowania gospodarki [Warczak, 2015, s. 112]. Zdaniem O. Lange rozwój gospodarczy to stały wzrost sił wytwórczych społeczeństwa, wzrost ilości i jakości dóbr materialnych i usług służących do zaspokojenia potrzeb ludzkich, to wzrost bogactwa i dobrobytu społeczeństw ludzkich [Lange, 1966, s. 144]. Analogiczna definicję rozwoju gospodarczego przedstawił G. Myrdal, który przyjmuje, że rozwój gospodarczy to wzrostowe zmiany całego systemu społecznego, obejmującego takie czynniki jak wydajności i dochód, 
warunki produkcji, poziom życia, postawy w stosunku do sposobu życia i pracy [Myrdal, 1968, s. 1859-1878]. Leszek Balcerowicz definiuje rozwój gospodarczy jako długofalową i masową poprawę materialnych warunków życia ludności np. poprawę warunków mieszkaniowych i wyżywienia, środków transportu i łączności [Balcerowicz, 1998, s. 35]. Pojęcie rozwoju gospodarczego jest mocno związane z pojęciem rozwoju społecznego. Rozwój społeczny to proces przemian społecznych, którego prawidłowy przebieg powoduje wzrost wartości istotnych dla danej zbiorowości zmiennych np. poprawa warunków bytu, rozwój kulturalny i naukowy. Wzajemne oddziaływanie rozwoju gospodarczego i rozwoju społecznego wynika z tego, że proces rozwoju gospodarczego odbywa się w społeczeństwach o określonej strukturze, które dysponuje określonym instytucjami społecznymi, politycznymi, normami prawnymi, wzorcami zachowań. Oznacza to, że rozwój gospodarczy nie jest możliwy bez zmian $\mathrm{w}$ zachowaniach społeczeństw oraz $\mathrm{w}$ funkcjonowaniu instytucji społecznych. Na proces rozwoju gospodarczego wpływ ma m.in. struktura demograficzna danego państwa. Od sytuacji demograficznej kraju zależy wielkość kapitału ludzkiego, który jest jednym z czynników rozwoju gospodarczego [Stacewicz, 2012, s. 182-183]. Istotna jest wielkość udziału ludzi w wieku produkcyjnym w liczbie ludności [Kołodko, 2002, s. 95].

Prognoza ludności Polski na lata 2015-2050 ukazuje głębokie zmiany w strukturze demograficznej (tabela 1).

TABELA 1.

Prognoza ludności według biologicznych grup wieku

\begin{tabular}{|l|c|c|}
\hline \multirow{2}{*}{ Wiek } & \multicolumn{2}{|c|}{ Rok } \\
\cline { 2 - 3 } & $\mathbf{2 0 1 5}$ & $\mathbf{2 0 5 0}$ \\
\hline $0-14$ & 14,9 & 12,1 \\
\hline $15-64$ & 69,3 & 55,2 \\
\hline $65+$ & 15,8 & 32,7 \\
\hline
\end{tabular}

Źródło: Prognoz̧a ludności na lata 2014-2050, GUS.

Zmniejszeniu o około 2.8 p.p. ulegnie liczba osób w wieku 0-14 i 14,1 p.p. w liczbie osób w przedziale wiekowym 15-64 lata. Wzrośnie natomiast udział osób w wielu 65+ z 15,8 p.p. w 2015 roku do 32,7 p.p. w 2050 roku. W związku z powyższym zmieni się także współczynnik obciążenia ekonomicznego. Współczynnik obciążenia ekonomicznego to stosunek liczby ludności w wieku poprodukcyjnym ${ }^{1}$ do liczby ludności w wieku produkcyjnym ${ }^{2}$. Prognozuje się, że stosunek ten zwiększy się w Polsce pomiędzy rokiem 2007 a 2030 z 24,8 do 43,7 osób w wieku poprodukcyjnym przypadających na 100 osób w wieku produkcyjnym [Starzenie sie spoteczeństwa ..., 2011, s. 5].

\footnotetext{
Kobiety w wieku 60 lat i więcej, mężczyźni w wieku 65 lat i więcej.

2 Kobiety w wieku 18-59 lat, mężczyźni w wieku 18-64 lata.
} 
Na zjawisko starzenia się ludności wpływa pośrednio wiele czynników, jak np. poziom zamożności społeczeństwa, promowany model rodziny, aktywność zawodowa kobiet, poziom opieki społecznej i ochrony zdrowia, wykształcenie ludności oraz polityka społeczna państwa [Starzenie sie społeczeństwa ..., 2011, s. 4].

\section{Syntetyczny miernik regionalnego zróżnicowania w zakresie rozwoju gospodarczego i struktury demograficznej w województwach w Polsce}

W badaniach dotyczących regionalnego zróżnicowania moga być stosowane różne podejścia metodyczne. W prowadzonych badaniach, narzędziem pozwalającym określić regionalne zróżnicowanie w zakresie rozwoju gospodarczego i struktury demograficznej wykorzystano syntetyczny miernik, który w sposób wiarygodny przedstawia obraz przemian zachodzących na mapie gospodarczej i demograficznej kraju, a także jest pomocny przy szacowaniu zmian zachodzących w poszczególnych regionach, dając możliwość porównań w czasie i w przestrzeni. Przeprowadzone badania w ujęciu dynamicznym pozwoliły na zbadanie zmian w poziomie rozwoju gospodarczego i struktury demograficznej, w poszczególnych jednostkach terytorialnych Polski.

Twórcą miary syntetycznego rozwoju jest Z. Hellwig, który wykorzystał miarę dla porównania poziomu rozwoju gospodarczego wybranych krajów. Miara rozwoju Hellwiga klasyfikuje badane zjawiska za pomoca jednej zagregowanej wielkości, które charakteryzowały się wieloma cechami.

Do danych służących do budowy syntetycznego miernika rozwoju gospodarczego i syntetycznego miernika sytuacji demograficznej społeczeństwa w poszczególnych województwach w Polsce zostały zaliczone wskaźniki opisujące rozwój gospodarczy kraju oraz wskaźniki opisujące strukturę demograficzną społeczeństwa.

Do wskaźników opisujących rozwój gospodarczy zaliczono:

- produkt krajowy brutto na jednego mieszkańca,

- $\quad$ stopę bezrobocia rejestrowego,

- współczynnik skolaryzacji (szkolnictwo ponadpodstawowe i ponadgimnazjalne).

Do wskaźników opisujących strukturę demograficzną społeczeństwa przyjęto :

- udział osób w wieku przedprodukcyjnym (14 lat i mniej),

- udział osób w wieku produkcyjnym: (15-59 lat kobiety, 15-64 lata mężczyźni),

- udział osób w wieku poprodukcyjnym (60 i więcej lat kobiety, 65 i więcej lat mężczyźni).

Następnie przystapiono do budowy syntetycznego miernika rozwoju gospodarczego i syntetycznego miernika sytuacji demograficznej w poszczególnych województwach. W pierwszym etapie określono charakter wpływu poszczególnych zmiennych na analizowane zjawisko i dokonano ich podziału na stymulanty i destymulanty. Wśród wskaźników opisujących rozwój gospodarczy do destymulant zaliczono stopę bezrobocia rejestrowego, a wśród wskaźników opisujących strukturę demograficzną społeczeństwa udział osób w wieku poprodukcyjnym. 
W drugim etapie ustalono system wag zmiennych, bowiem każdą cechę można określić jako tak samo ważną lub można ustalić system wag. W badaniu wszystkim cechom nadano wagę równą 1 , nadając tym samym wszystkim cechom jednakowe znaczenie.

W kolejnym etapie przekształcono destymulanty $\left\{\mathrm{X}_{\mathrm{d}}\right\}$ na stymulanty $\left\{\mathrm{X}_{\mathrm{s}}\right\}$, aby wszystkie cechy wywierały pozytywny wpływ na badane zjawisko w tym samym kierunku (pozytywnie). Po dokonaniu przekształceń wszystkie cechy będą wpływać na badane zjawisko w tym samym kierunku czyli dodatnio ${ }^{3}$. Wykonano to przy pomocy następującego wzoru:

$$
\begin{gathered}
X_{i t}=\frac{1}{X_{i t^{\prime}}} \\
(\mathrm{i}=1,2, \ldots \ldots, \mathrm{k} ; \mathrm{t}=1,2, \ldots \ldots, \mathrm{n})
\end{gathered}
$$

gdzie:

$\mathrm{X}_{\mathrm{it}}$ - stymulanta

$\mathrm{X}_{\text {it }}^{\prime}$ - destymulanta

W etapie czwartym dokonano normalizacji zmiennych, gdzie za pomocą standaryzacji doprowadzono je do porównywalności i jednorodności. Standaryzacja zmiennych polega na wyrównaniu wariancji wszystkich zmiennych diagnostycznych i sprowadzeniu ich do jedności.

Uzyskuje się to w następujący sposób:

gdzie:

$$
Z_{i t}=\frac{x_{i t}-\bar{x}_{l}}{s_{i}}
$$

$$
\begin{gathered}
x_{i}=\frac{1}{n} \sum_{t=1}^{n} x_{i t} \\
S_{i}=\left[\frac{1}{n} \sum_{i=1}^{n}\left(x_{i t}-x_{i}\right)^{2}\right]^{0,5}
\end{gathered}
$$

$\mathrm{Z}_{\mathrm{it}}-$ zestandaryzowana wartość zmiennej diagnostycznej $\mathrm{X}_{\mathrm{i}} \mathrm{w}$ obiekcie (jednostce czasu ) o numerze t.

Etapem piątym był wybór wzorca rozwoju gospodarczego i wzorca sytuacji demograficznej społeczeństwa. Wybór wzorca rozwoju - wzorcem staje się jednostka abstrakcyjna, której współrzędne określone zostały przez maksymalne, czyli największe wartości:

$$
z_{i t}=\max _{t} z_{i t}
$$

3 Wzór do przekształceń destymulant w stymulanty można znaleźć w pracy K. Logwiniuk, 2011, Zastosowanie metod taksonomicznych $w$ analizie porównawcrej dostępu do infrastruktury ICT przez mtodzie z. szkelnq w Polsce, „Economy and Management”, nr 1, s. 11. 
Kolejnym etapem było wyznaczenie dla każdego województwa odległości od wyznaczonego wzorca rozwoju gospodarczego czy struktury demograficznej $\left(\mathrm{d}_{\mathrm{t}}\right)$, która jest wykorzystywana do porównywania rozwoju zjawiska w wyróżnionych obiektach (jednostkach czasu). Zbudowaną w ten sposób odległość interpretuje się w następujący sposób - im większą wartość przyjmuje wielkość $d_{t}$ tym mniejszy poziom rozwoju badanego zjawiska osiagnęło dane województwo.

$$
d_{t}=\left[\sum_{i-1}^{k}\left(z_{i t}-z_{i o}\right)^{2}\right]^{0,5}
$$

Utworzona $\mathrm{w}$ ten sposób zmienna syntetyczna nie jest unormowana. W celu unormowania zmiennej syntetycznej $\mathrm{d}_{\mathrm{t}} \mathrm{i}$ otrzymania takiej miary, której rosnące wartości świadczyłyby o rozwoju badanego zjawiska konstruuje się tzw. względną zmienną syntetyczna (inaczej syntetyczny miernik), która z prawdopodobieństwem bliskim jedności przyjmuje wartości z przedziału $[0,1]$ o postaci:

gdzie:

$$
Z_{t}=1-\frac{d_{t}}{d_{o}}
$$

przy czym:

$$
d_{o}=\bar{d}+2 S_{d}
$$

natomiast:

$$
\bar{d}=\frac{1}{n} \sum_{t=1}^{n} d_{t}
$$

$$
S_{d}=\left[\frac{1}{n} \sum_{t=1}^{n}\left(d_{t}-\bar{d}\right)^{2}\right]^{0,5}
$$

Gdy wartość $z_{\mathrm{t}}$ bardziej oscyluje wokół 1, tym rozwój zjawiska w analizowanym obiekcie mniej różni się od rozwoju obiektu modelowego opisanego za pomocą maksymalnych realizacji zmiennych diagnostycznych. W przypadku, gdy $z_{t}$ przyjmuje wartość ujemna, jest bliskie zeru lub oscyluje wokół zera, to rozwój badanego obiektu jest zdecydowanie słabszy od rozwoju pozostałych obiektów4

Przeprowadzone badania wykazały, że największe podobieństwo do wzorcowego województwa w analizowanych latach posiadało województwo mazowieckie, gdzie $z_{\mathrm{t}} \mathrm{w} 2006$ roku wynosiło 0,96, a w 2015 roku 0,97. Najmniejsze podobieństwo do wzorcowego województwa odnotowano w województwie warmińsko-mazurskim zarówno dla roku 2006 jak i 2015, wartość $z_{\mathrm{t}}$ wynosiła odpowiednio 0,16 i 0,12. Porównując rok 2015 w stosunku do roku 2006 tylko w województwie śląskim wartość nie zmniejszyła się, lecz nastapił minimalny wzrost odległości od wzorca

4 Porównaj: [Hellwig, 1968, s. 324; Nowak, 1984, s. 118; Taksonomiczna analiza przestrzennego ..., 2000, s. 91-93]. 
rozwoju gospodarczego według syntetycznego miernika czyli nastapiła poprawa rozwoju gospodarczego. W pozostałych województwach wielkość ta uległa zmniejszeniu, co oznacza, że rozwój gospodarczy w tych województwach pogorszył się w stosunku do wzorcowego województwa (wykres 1).

WYKRES 1.

Odległości województw Polski od wzorca rozwoju gospodarczego według syntetycznego miernika w latach 2006 i 2015

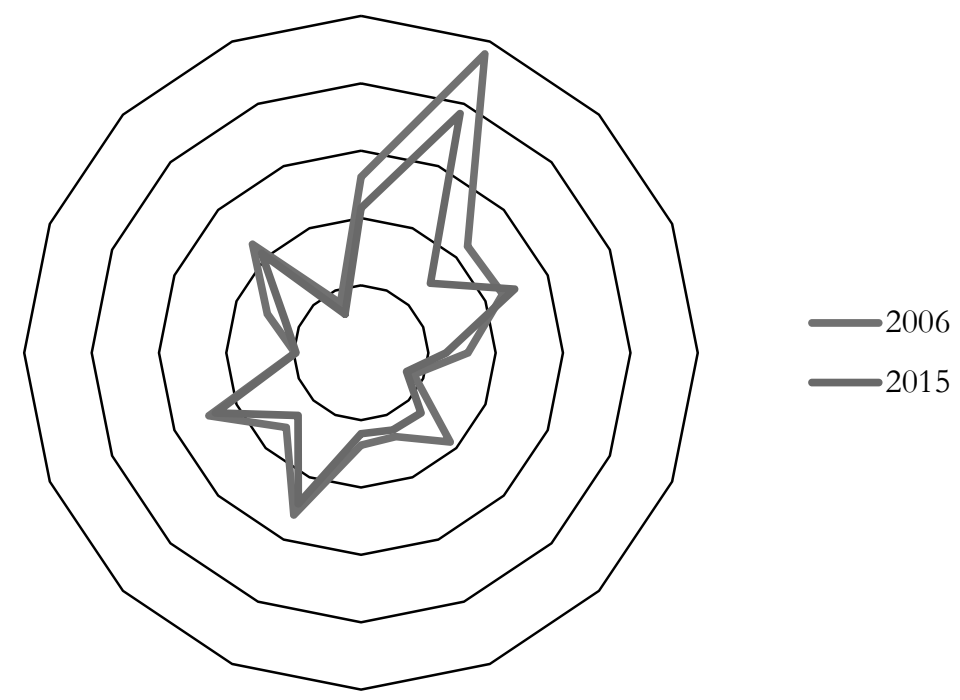

Źródło: opracowanie własne.

W przypadku sytuacji demograficznej społeczeństwa badania wykazały, że największe podobieństwo do wzorcowego województwa w analizowanych latach posiadało województwo warmińsko-mazurskie, gdzie $z_{\mathrm{t}} \mathrm{w} 2006$ roku wynosiło 0,79, a w 2015 roku 0,84. Najmniejsze podobieństwo do wzorcowego województwa odnotowano w województwie łódzkim, zarówno dla roku 2006 jak i 2015, wartość $z_{t}$ wynosiła odpowiednio 0,13 i 0,01. Analizując rok 2015 w stosunku do roku 2006 w sześciu województwach: mazowieckim, małopolskim, lubelskim, podkarpackim, podlaskim i warmińsko-mazurskim nie zwiększyła się odległość od wzorca sytuacji demograficznej społeczeństwa czyli nastapiła poprawa tej sytuacji. W pozostałych województwach wielkość ta uległa zwiększeniu, co oznacza, że sytuacja demograficzna społeczeństw w tych województwach pogorszyła się (wykres 2). 
WYKRES 2.

Odległości województw Polski od wzorca sytuacji demograficznej społeczeństwa według syntetycznego miernika w latach 2006 i 2015

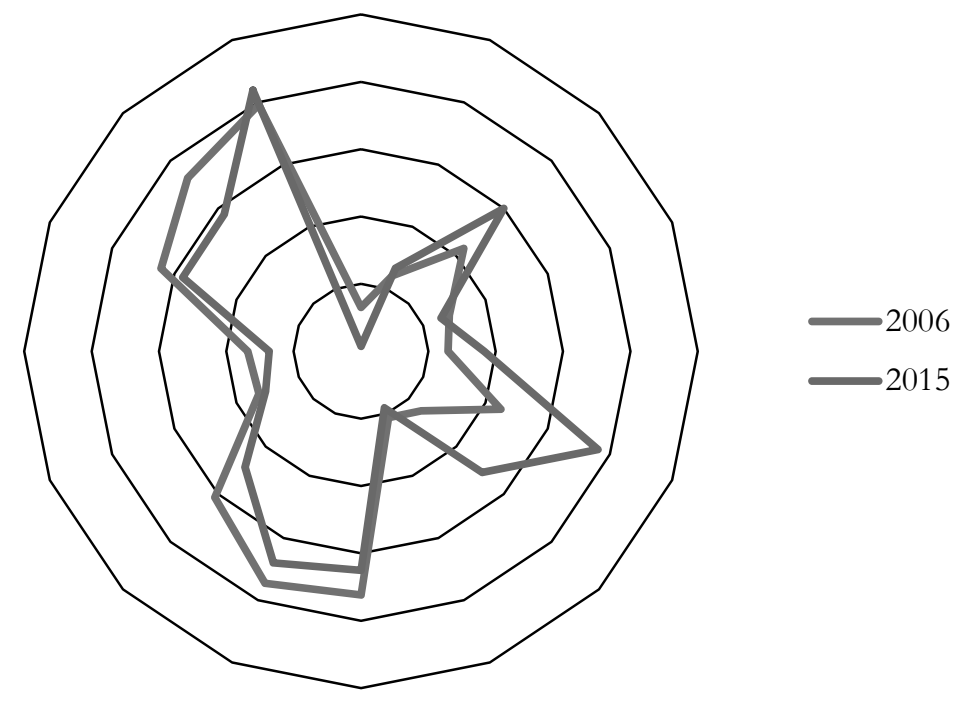

Źródło: opracowanie własne.

Obliczone wartości zmiennych syntetycznych stanowia podstawę do sporządzenia rankingu województw od najlepszego do najsłabszego względem analizowanych zjawisk i lat (tabela 2).

Sporządzony ranking wykazał, że w zakresie rozwoju gospodarczego według syntetycznego miernika $w$ analizowanych latach nie zmieniła się pozycja na liście rankingowej następujących województw: mazowieckiego, wielkopolskiego, dolnoślaskiego, pomorskiego, małopolskiego, lubelskiego, opolskiego, podkarpackiego, warmińsko-mazurskiego. W rankingu wyższa pozycję w 2015 roku w stosunku do roku 2006 odnotowano dla województw: śląskiego, zachodniopomorskiego, świętokrzyskiego, a niższa pozycję dla województw: podlaskiego, kujawsko-pomorskiego, lubuskiego i łódzkiego. 
TABELA 2.

Ranking województw względem rozwoju gospodarczego i sytuacji demograficznej społeczeństwa według syntetycznego miernika

\begin{tabular}{|c|c|c|c|c|}
\hline \multirow[b]{2}{*}{$\begin{array}{c}\text { Pozycja } \\
\text { w ran- } \\
\text { kingu }\end{array}$} & \multicolumn{2}{|c|}{ Rozwój gospodarczy } & \multicolumn{2}{|c|}{ Sytuacja demograficzna } \\
\hline & 2006 & 2015 & 2006 & 2015 \\
\hline 1 & mazowieckie & mazowieckie & $\begin{array}{l}\text { warmińsko- } \\
\text { mazurskie }\end{array}$ & $\begin{array}{l}\text { warmińsko- } \\
\text { mazurskie }\end{array}$ \\
\hline 2 & łódzkie & śląskie & wielkopolskie & podkarpackie \\
\hline 3 & wielkopolskie & wielkopolskie & pomorskie & wielkopolskie \\
\hline 4 & dolnośląskie & dolnośląskie & lubuskie & lubuskie \\
\hline 5 & śląskie & łódzkie & $\begin{array}{l}\text { kujawsko- } \\
\text { pomorskie }\end{array}$ & małopolskie \\
\hline 6 & pomorskie & pomorskie & $\begin{array}{l}\text { zachodnio- } \\
\text { pomorskie }\end{array}$ & pomorskie \\
\hline 7 & małopolskie & małopolskie & podkarpackie & $\begin{array}{l}\text { kujawsko- } \\
\text { pomorskie }\end{array}$ \\
\hline 8 & podlaskie & $\begin{array}{l}\text { zachodnio- } \\
\text { pomorskie }\end{array}$ & małopolskie & podlaskie \\
\hline 9 & lubelskie & lubelskie & opolskie & $\begin{array}{l}\text { zachodnio- } \\
\text { pomorskie }\end{array}$ \\
\hline 10 & $\begin{array}{l}\text { zachodnio- } \\
\text { pomorskie }\end{array}$ & podlaskie & dolnośląskie & lubelskie \\
\hline 11 & $\begin{array}{l}\text { kujawsko- } \\
\text { pomorskie }\end{array}$ & świętokrzyskie & śląskie & dolnośląskie \\
\hline 12 & lubuskie & $\begin{array}{l}\text { kujawsko- } \\
\text { pomorskie }\end{array}$ & lubelskie & opolskie \\
\hline 13 & świętokrzyskie & lubuskie & podlaskie & mazowieckie \\
\hline 14 & opolskie & opolskie & mazowieckie & śląskie \\
\hline 15 & podkarpackie & podkarpackie & świętokrzyskie & świętokrzyskie \\
\hline 16 & $\begin{array}{l}\text { warmińsko- } \\
\text { mazurskie }\end{array}$ & $\begin{array}{l}\text { warmińsko- } \\
\text { mazurskie }\end{array}$ & łódzkie & łódzkie \\
\hline
\end{tabular}

Źródło: opracowanie własne.

W zakresie sytuacji demograficznej społeczeństwa według syntetycznego miernika $\mathrm{w}$ analizowanych latach nie zmieniła się pozycja na liście rankingowej następujących województw: warmińsko-mazurskiego, lubuskiego, świętokrzyskiego i łódzkiego. W rankingu wyższa pozycję w 2015 roku w stosunku do roku 2006 odnotowano dla województw: podkarpackiego, małopolskiego, lubelskiego, podlaskiego i mazowieckiego, a niższa pozycję dla województw wielkopolskiego, pomorskiego, 
kujawsko-pomorskiego, zachodniopomorskiego, opolskiego, dolnośląskiego i śląskiego.

Następnie utworzono dla analizowanych lat wspólny ranking badanych zjawisk. Dla województwa, które było na liście rankingowej na pierwszym miejscu przypisano 16 punktów, dla województwa znajdującego się na drugim miejscu przypisano 15 punktów i tak do województwa będącego na ostatnim miejscu, któremu nadano 1 punkt. Po przypisaniu punktów do wszystkich województw zsumowano je (tabela 3).

TABELA 3.

Ranking województw względem rozwoju gospodarczego i sytuacji demograficznej społeczeństwa łącznie według syntetycznego miernika

\begin{tabular}{|l|l|c|l|c|}
\hline \multirow{2}{*}{$\begin{array}{c}\text { Pozycja } \\
\mathbf{w} \\
\text { rankingu }\end{array}$} & \multicolumn{4}{|c|}{ Rok } \\
\cline { 2 - 5 } & Województwo & $\begin{array}{c}\text { Liczba uzyskanych } \\
\text { punktów }\end{array}$ & Województwo & $\begin{array}{c}\text { Liczba uzyskanych } \\
\text { punktów }\end{array}$ \\
\hline 1 & wielkopolskie & 29 & wielkopolskie & 28 \\
\hline 2 & pomorskie & 25 & małopolskie & 22 \\
\hline 3 & dolnoślaskie & 20 & pomorskie & 22 \\
\hline 4 & małopolskie & 19 & mazowieckie & 20 \\
\hline 5 & mazowieckie & 19 & dolnośląskie & 19 \\
\hline 6 & $\begin{array}{l}\text { kujawsko- } \\
\text { pomorskie }\end{array}$ & 18 & ślaskie & 18 \\
\hline 7 & lubuskie & 18 & lubuskie & 17 \\
\hline 8 & śląskie & 18 & podkarpackie & 17 \\
\hline 9 & $\begin{array}{l}\text { zachodnio- } \\
\text { pomorskie }\end{array}$ & 18 & $\begin{array}{l}\text { warmińsko- } \\
\text { mazurskie }\end{array}$ & 17 \\
\hline 10 & $\begin{array}{l}\text { warmińsko- } \\
\text { mazurskie }\end{array}$ & 17 & $\begin{array}{l}\text { zachodnio- } \\
\text { pomorskie }\end{array}$ & 17 \\
\hline 11 & łódzkie & 16 & podlaskie & 16 \\
\hline 12 & lubelskie & 13 & $\begin{array}{l}\text { kujawsko- } \\
\text { pomorskie }\end{array}$ & 15 \\
\hline 13 & podlaskie & 13 & lubelskie & 15 \\
\hline 14 & podkarpackie & 12 & lódzkie & 13 \\
\hline 15 & opolskie & 11 & opolskie & 8 \\
\hline 16 & świętokrzyskie & 6 & świętokrzyskie & 8 \\
\hline
\end{tabular}

Źródło: opracowanie własne.

Ustalając ranking województw pod względem rozwoju gospodarczego i w zakresie struktury demograficznej w analizowanych latach badania wykazały, że najlepsza sytuacja wystapiła w województwie wielkopolskim. Najgorszą sytuację pod względem analizowanych zjawisk odnotowano w województwie świętokrzyskim. Najwięk- 
szy skok w powyższym rankingu odnotowano dla województwa podkarpackiego o 6 miejsc, a największy spadek dla województwa kujawsko-pomorskiego, także o 6 miejsc.

\section{Podsumowanie}

Analizie taksonomicznej rozwoju gospodarczego i struktury demograficznej poddano 16 województw Polski. Uzyskane wyniki wskazują, że w latach 2006 i 2015 w czołówce województw, najbardziej zbliżonych do wzorca, a tym samym posiadających najwyższy poziom rozwoju społecznego i najlepszą strukturę demograficzną jest województwo wielkopolskie. Podsumowując przeprowadzone badania należy podkreśić, że pod względem analizowanych zjawisk nadal w Polsce występuja regiony, które należy wspierać, aby wyrównać szanse ich mieszkańców na lepsze życie. Zmniejszenie dysproporcji rozwojowych wymaga jednak dłuższego czasu. Dodatkowo należy uwzględnić fakt postępującego zjawiska starzenia się społeczeństwa. Wszystkie te czynniki wymagaja prowadzenia odpowiedniej polityki społeczno-gospodarczej uwzględniającej zmiany w zakresie struktury siły roboczej i wzrostu zapotrzebowania na niektóre usługi, szczególnie w dziedzinie ochrony zdrowia oraz opieki społecznej, a także kształtowania zmian w modelu rodziny.

\section{Literatura}

Balcerowicz L., 1998, Wolność i rozuój. Ekonomia wolnego rynku, Wydawnictwo Znak, Kraków.

Hellwig Z., 1968, Zastosowanie metody taksonomicznej do typologicznego podziatu krajón ze wagledu na poziom ich rozpoju i strukture wykewalifikowanych kadr, „Przegląd Statystyczny" nr 4.

Kurek S., 2008, Typologia starzenia się ludności Polski w ujecin przestrzennym, Wydawnictwo Akademii Pedagogicznej im. Komisji Edukacji Narodowej w Krakowie, Kraków.

Lange O., 1966, O socjalizmie i gospodarce socjalistycznej, PWN, Warszawa.

Logwiniuk K., 2011, Zastosowanie metod taksonomicznych w analizie porównawczej dostepu do infrastruktury ICT pręez, mtodzież sžolnq w Polsce, „Economy and Management”, nr 1.

Kołodko G., 2002, Rozwój polskiej gospodarki, perspektywy i uwarunkowania, Wydawnictwo Wyższej Szkoły Przedsiębiorczości i Zarządzania im. Leona Koźmińskiego, Warszawa.

Myrdal G., 1968, Asian Drama, An Inquiry into the Poverty of Nations, vol. III, New York.

Noga M., 2008, Co decyduje o rozwoju gospodarcaym, [w:] J. Koch, Wærost gospodarçy a innowacje, Politechnika Wrocławska Wrocławskie Centrum Transferu Technologii, Wrocław.

Nowak E., 1984, Problemy doboru zmiennych do modelu ekonometrycznego, PWN, Warszawa. 
Stacewicz J., 2012, Kluczowe cąynniki roz̧woju w gospodarce opartej na wiedzy, Prace i Materiały Instytutu Rozwoju Gospodarczego SGH, IRG SGH, Warszawa.

Starzenie sie spoteczeństwa polskiego i jego skutki, 2011, Opracowania Tematyczne OT601 Kancelaria Senatu, Warszawa.

Warczak M., 2015, Endogeniczne i egzogeniczne czynniki rozwoju gospodarczego z perspektyny finansów gminy, „Współczesna Gospodarka”, t. 6, nr 4.

Taksonomiczna analiza przestrzennego zróżnicowania poziomu sycia w Polsce w ujeciu dynamicznym, 2000, A. Zeliaś (red.), AE w Krakowie, Kraków. 